\title{
Calculation of Grounding Grids Parameter at Arbitrary Geometry
}

\author{
Carlos L. B. Silva, Thyago G. Pires, Wesley P. Calixto, Diogo N. Oliveira, Luis A. P. Souza and \\ Antonio M. Silva Filho
}

\begin{abstract}
This paper deals with the computation of ground resistance, surface voltage, touch voltage and step voltage, to mesh with horizontal wires arranged in different angles. The computer program implemented used in the mathematical modeling is based on the method proposed by Heppe, which allows obtaining the grounding parameters for homogeneous soil and soil stratified in two layers. The results obtained with the proposed method will be compared with other methods in literature. Also will be presented the results of a grounding grid using wires at various angles.
\end{abstract}

Index Terms- Grounding grids parameters, Heppe, soil stratified in two layers.

\section{INTRODUCTION}

$\mathrm{T}$ HE study and analysis of grounding grids brings great concern to engineers, as is the initial step in the process of building a substation. The main purpose of the grounding grid design is to keep the step voltages, touch and electrical resistance to earth within tolerable limits [1].

The classic method of grounding grid design [2] is a method that does not require computing resources and its intended to be easy to use. However, it has some limitations for heterogeneous soil, to the analysis of potential on the ground's surface and the geometry of the ground grid. It can only be used in cases where the wires are equidistant and in grounding grids with the following shapes: square, rectangular, L-shape and T-shape.

The geometry of the grounding grid depends on the area of the substation [3] and several studies prove a greater effectiveness of the unequally spaced grounding grids as regards the trend the touch voltages [4].

The methodology used in this paper to obtain the ground resistance and the potential on the soil surface is based on Heppe [5] using the method of images and the average potential method. The examples shown in [5] used only grids containing conductors placed in parallel and perpendicular to each other, deployed on homogeneous soil. However, our method enables the use of meshes in any relative positions with conductors placed in soil stratified in two layers.

The computer program was developed to implement the mathematical model and allows the calculation of the grounding potential rise, the potential on the soil surface and the ground resistance. The touch voltages and the step voltages obtained from de surface potential.
Some results of grounding grids will be presented in standard formats, which are compared with traditional methods. Results of a ground grid of unconventional geometry are also presented.

\section{METHODOLOGY}

The grid conductors are conceptually divided in rectilinear segments in order to discretize the system. The accuracy of the modeling is associated with the number of segments used. The greater the number of segments, the more precise is the modeling.

In each segment, it is considered that the distribution of leakage current is constant throughout its length, but distinct from segment to segment. It is assumed that all segments have the same voltage, which is equal to the ground potential rise (GPR).

After the division, the leakage current of each segment and GPR are calculated. Then, the leakage current is used to calculate the ground resistance and the voltage at the ground surface at any desired point. To find the leakage current (i) in each segment the linear equation shown in (1) must be solved. Where $\mathrm{m}$ is the number of segments.

$$
\begin{aligned}
& R_{11} \cdot i_{1}+R_{12} \cdot i_{2}+R_{13} \cdot i_{3}+\cdots+R_{1 m} \cdot i_{m}=v_{1} \\
& R_{21} \cdot i_{1}+R_{22} \cdot i_{2}+R_{23} \cdot i_{3}+\cdots+R_{2 m} \cdot i_{m}=v_{2} \\
& R_{31} \cdot i_{1}+R_{32} \cdot i_{2}+R_{33} \cdot i_{3}+\cdots+R_{3 m} \cdot i_{m}=v_{3} \\
& \quad \vdots \\
& R_{m 1} \cdot i_{1}+R_{m 2} \cdot i_{2}+R_{m 3} \cdot i_{3}+\cdots+R_{m m} \cdot i_{m}=v_{m}
\end{aligned}
$$

The above system can be written in matrix form as:

$$
\left[\begin{array}{ccccc}
R_{11} & R_{12} & R_{13} & \cdots & R_{1 m} \\
R_{21} & R_{22} & R_{23} & \cdots & R_{2 m} \\
R_{31} & R_{32} & R_{33} & \cdots & R_{3 m} \\
\vdots & \vdots & \vdots & \ddots & \vdots \\
R_{m 1} & R_{m 2} & R_{m 3} & \cdots & R_{m m}
\end{array}\right] \cdot\left[\begin{array}{c}
i_{1} \\
i_{2} \\
i_{3} \\
\vdots \\
i_{m}
\end{array}\right]=\left[\begin{array}{c}
v_{1} \\
v_{2} \\
v_{3} \\
\vdots \\
v_{m}
\end{array}\right]
$$

The total current injected into the grid $\left(i_{g}\right)$ is equal to the sum of leakage current of all segments, as shown in (3).

$$
\sum_{k=1}^{m} i_{k}=i_{g}
$$


Appending (3) in (2), we have:

$$
\left[\begin{array}{cccccc}
R_{11} & R_{12} & R_{13} & \cdots & R_{1 m} & -1 \\
R_{21} & R_{22} & R_{23} & \cdots & R_{2 m} & -1 \\
R_{31} & R_{32} & R_{33} & \cdots & R_{3 m} & -1 \\
\vdots & \vdots & \vdots & \ddots & \vdots & \vdots \\
R_{m 1} & R_{m 2} & R_{m 3} & \cdots & R_{m m} & -1 \\
1 & 1 & 1 & \cdots & 1 & 0
\end{array}\right] \cdot\left[\begin{array}{c}
i_{1} \\
i_{2} \\
i_{3} \\
\vdots \\
i_{m} \\
G P R
\end{array}\right]=\left[\begin{array}{c}
0 \\
0 \\
0 \\
\vdots \\
0 \\
i_{g}
\end{array}\right]
$$

Thus the GPR becomes a system variable, because the total current injected into the grid is usually a project information and not the potential of electrodes.

Next, computation of mutual and self-resistance of (4), the ground resistance and voltages will be explained. All terms are calculated for each individually segment, without any symmetry of the grid as used in [5]. To calculate the mutual resistance and the voltage at the ground surface the method of images is used.

\section{A. Mutual Resistance}

The mutual resistance $\left(R_{j k}\right)$ is the ratio of the voltage produced on the segment $k$ by leakage current of segment $j$. The symmetry of mutual resistance allows. The self-resistance $\left(R_{j j}\right)$ is the ratio between the voltages produced on the segment by its own leakage current.

Considering a soil composed of two layers with the upper layer having resistivity $\rho_{l}$ and depth $H$, and lower layer having resistivity $\rho_{2}$ and extending to a great depth. The mutual resistance between a segment $j$ and a segment $k$, and their images, buried at the same depth $(D)$ in the upper layer of soil is given by (5) and in the bottom layer is given by (6).

Considering a soil composed of two layers with the upper layer having resistivity $\rho_{l}$ and depth $H$, and lower layer having resistivity $\rho_{2}$ and extending to a great depth. The mutual resistance between a segment $j$ and a segment $k$, and their images, buried at the same depth $(D)$ in the upper layer of soil is given by (5) and in the bottom layer is given by (6).

Fig. 1 is the corresponding diagram to the terms of (8) and (9). The images of segment are in different planes. The point $C$ is in the same plane of segment $A B$ and point $G$ is in the same plane of segment $E F$.

$$
\begin{aligned}
R_{j k}= & \frac{\rho_{1}}{4 \cdot \pi \cdot L_{j} \cdot L_{k}} \cdot \\
& \left\{\sum_{n=0}^{\infty} K^{n} \cdot[M(2 \cdot n \cdot H)+M(2 \cdot n \cdot H+2 \cdot D)]+\right. \\
& \left.\sum_{n=1}^{\infty} K^{n} \cdot[M(2 \cdot n \cdot H)+M(2 \cdot n \cdot H-2 \cdot D)]\right\} \\
R_{j k}= & \frac{\rho_{2}}{4 \cdot \pi \cdot L_{j} \cdot L_{k}} \cdot[M(0)-K \cdot M(2 \cdot H-2 \cdot D)+ \\
& \left.\left(1-K^{2}\right) \cdot \sum_{n=0}^{\infty} K^{n} \cdot M(2 \cdot n \cdot H+2 \cdot D)\right]
\end{aligned}
$$

Where $K$ is the reflection factor.

$$
K=\frac{\rho_{2}-\rho_{1}}{\rho_{2}+\rho_{1}}
$$

The term $M$ is given by (8), for $0 \leq \theta \leq \pi$.

$$
\begin{aligned}
M(C G)= & \underline{C B} \cdot \ln \left(\frac{B F+\underline{B^{\prime} F}}{B E+\underline{B^{\prime} E}}\right)-\underline{C A} \cdot \ln \left(\frac{A F+\underline{A^{\prime} F}}{A E+\underline{A^{\prime} E}}\right)+ \\
& \underline{G F} \cdot \ln \left(\frac{B F+\underline{F^{\prime} B}}{A F+\underline{F^{\prime} A}}\right)-\underline{G E} \cdot \ln \left(\frac{B E+\underline{E^{\prime} B}}{A E^{\prime}+\underline{E^{\prime} A}}\right)- \\
& \frac{C G \cdot \delta}{\sin \theta}
\end{aligned}
$$

The term $\delta$ is the following equation:

$$
\begin{aligned}
\delta=\tan ^{-1} & \left(\frac{C G}{B F \cdot \tan \theta}+\frac{\underline{C B}}{C G} \cdot \frac{G F \cdot \sin \theta}{B F}\right) \\
& -\tan ^{-1}\left(\frac{C G}{B E \cdot \tan \theta}+\frac{\underline{C B}}{C G} \cdot \frac{G E \cdot \sin \theta}{B E}\right) \\
& -\tan ^{-1}\left(\frac{C G}{A F \cdot \tan \theta}+\frac{\underline{C A}}{C G} \cdot \frac{\frac{G F}{\cos \theta}}{A F}\right) \\
& +\tan ^{-1}\left(\frac{C G}{A E \cdot \tan \theta}+\frac{\left.\frac{C A}{C G} \cdot \frac{G E \cdot \sin \theta}{A E}\right)}{A E}\right.
\end{aligned}
$$

In the case of parallel segments, when $\theta$ decrease towards zero, the term $C G . \Omega / \sin \theta$ approaches $B E+A F-B F-A E$.

To compute the self-resistance a hypothetical segment parallel and identical to the original segment separated by a distance equal to the radius of the conductor is considered.

\section{B. Ground Resistance}

The ground resistance $\left(R_{g}\right)$ is the ratio between the GPR, computation with (4), and the total current injected into the grid.

$$
R_{g}=G P R / i_{t}
$$

\section{Voltage on Soil Surface}

Once the leakage currents in each segment is found, the voltage at a point on the soil surface due to the contribution of a leakage current of a segment located in a upper layer is

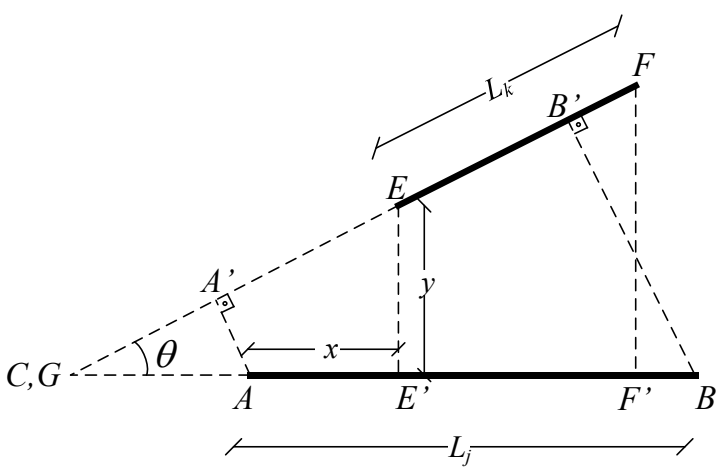

Fig. 1. Angled segments. 
calculated by (11) and of a segment located in a bottom layer is calculated by (12).

$$
\begin{aligned}
V= & \frac{i \cdot \rho_{1}}{2 \cdot \pi \cdot L} \cdot\left\{\ln \left(\frac{\sqrt{x^{2}+y^{2}+D^{2}}+x}{\sqrt{(x-L)^{2}+y^{2}+D^{2}}+x-L}\right)+\right. \\
& \sum_{n=1}^{\infty} K^{n} \cdot\left[\ln \left(\frac{\sqrt{x^{2}+y^{2}+(2 \cdot n \cdot H+D)^{2}}+x}{\sqrt{(x-L)^{2}+y^{2}+(2 \cdot n \cdot H+D)^{2}}+x-L}\right)+\right. \\
& \left.\left.\ln \left(\frac{\sqrt{x^{2}+y^{2}+(2 \cdot n \cdot H-D)^{2}}+x}{\sqrt{(x-L)^{2}+y^{2}+(2 \cdot n \cdot H-D)^{2}}+x-L}\right)\right]\right\} \\
V= & \frac{\rho_{1} \cdot i \cdot(1+K)}{2 \cdot \pi \cdot L} \cdot\left\{\ln \left(\frac{\sqrt{\left(x_{p}-L\right)^{2}+y_{p}^{2}+D^{2}}+L-x_{p}}{\sqrt{x_{p}^{2}+y_{p}^{2}+D^{2}}-x_{p}}\right)+\right. \\
& \left.\sum_{n=1}^{\infty} K^{n} \cdot\left[\ln \left(\frac{\sqrt{\left(x_{p}-L\right)^{2}+y_{p}^{2}+(2 \cdot n \cdot H+D)^{2}}+L-x_{p}}{\sqrt{x_{p}^{2}+y_{p}^{2}+(2 \cdot n \cdot H+D)^{2}}-x_{p}}\right)\right]\right\}
\end{aligned}
$$

Therefore, the voltage at a point on the soil surface is calculated by superposition, by the sum of the contribution of all segments.

\section{Touch, Mesh and Step Voltages}

With the surface voltages, the other voltages can be determined. The touch voltages is the potential difference between the GPR of a ground grid and the surface potential at the point where a person could be standing while at the same time having a hand in contact with a grounded structure. Furthermore, the mesh voltage is the maximum touch voltage within a mesh of ground grid. Moreover, the step voltage is the difference in surface potential that could be experienced by a person a distance of $1 \mathrm{~m}$ with the feet without contacting any grounded object.

\section{RESULTS}

Three case studies are presented. The case studies 1 and 2 perform the validation of the proposed method by comparing VCM with traditional methods. Case study 1 compare the values of the ground resistance of the grids with square mesh by other methods. Case study 2 compare the ground resistance, mesh voltage and step voltage with the design procedure in [6]. Finally, case study 3 show the results for an unconventional grid.

\section{A. Case Study 1}

Table I shows the ground resistance values for a square grid $(20 \mathrm{~m} \times 20 \mathrm{~m})$ and a rectangular grid $(40 \mathrm{~m} \times 10 \mathrm{~m})$ in homogeneous soil. The ground resistance values are calculated using the simplified calculations provided in the ANSI-IEEE Std. 80/2013: Dwight [7], Laurent and Nieman [6], Sverak [8] and Schwarz [9]. In addition to the calculations presented by Nahman [10] and Chow [11]. The BEM method (Boundary Element Method) is obtained from [12] and VCM is computed with the method presented in this paper. The values in parentheses are the percentage differences from the values calculated by VCM [15].

\begin{tabular}{|c|c|c|c|c|}
\hline \multirow{2}{*}{ Method } & \multicolumn{2}{|c|}{$\begin{array}{l}\text { Square } \\
(20 \mathrm{~m} \times 20 \mathrm{~m})\end{array}$} & \multicolumn{2}{|c|}{$\begin{array}{l}\text { Rectangular } \\
(40 \mathrm{mx} 10 \mathrm{~m})\end{array}$} \\
\hline & $\begin{array}{l}4 \\
\text { meshes }\end{array}$ & $\begin{array}{l}16 \\
\text { meshes }\end{array}$ & $\begin{array}{l}4 \\
\text { meshes }\end{array}$ & $\begin{array}{l}16 \\
\text { meshes }\end{array}$ \\
\hline Dwight & $\begin{array}{l}2.2156 \\
(15.9 \%)\end{array}$ & $\begin{array}{l}2.2156 \\
(6.4 \%)\end{array}$ & $\begin{array}{l}2.2156 \\
(6.8 \%)\end{array}$ & $\begin{array}{l}2.2156 \\
(3.2 \%)\end{array}$ \\
\hline Laurent & $\begin{array}{l}3.0489 \\
(15.7 \%)\end{array}$ & $\begin{array}{l}2.7156 \\
(14.7 \%)\end{array}$ & $\begin{array}{l}2.9848 \\
(25.5 \%)\end{array}$ & $\begin{array}{l}2.6918 \\
(25.4 \%)\end{array}$ \\
\hline Sverak & $\begin{array}{l}2.9570 \\
(12.2 \%)\end{array}$ & $\begin{array}{l}2.6236 \\
(10.8 \%)\end{array}$ & $\begin{array}{l}2.8929 \\
(21.6 \%)\end{array}$ & $\begin{array}{l}2.5998 \\
(21.1 \%)\end{array}$ \\
\hline Schwarz & $\begin{array}{l}2.8084 \\
(6.6 \%)\end{array}$ & $\begin{array}{l}2.6035 \\
(10.0 \%)\end{array}$ & $\begin{array}{l}2.4690 \\
(3.8 \%)\end{array}$ & $\begin{array}{l}2.3211 \\
(8.15 \%)\end{array}$ \\
\hline Nahman & $\begin{array}{l}3.6367 \\
(38.1 \%)\end{array}$ & $\begin{array}{l}3.1491 \\
(33.0 \%)\end{array}$ & - & - \\
\hline Chow & $\begin{array}{l}4.8017 \\
(82.3 \%)\end{array}$ & $\begin{array}{l}3.2621 \\
(37.8 \%)\end{array}$ & - & - \\
\hline BEM & $\begin{array}{l}2.6269 \\
(0.3 \%)\end{array}$ & $\begin{array}{l}2.3631 \\
(0.2 \%)\end{array}$ & $\begin{array}{l}2.2734 \\
(4.4 \%)\end{array}$ & $\begin{array}{l}2.0795 \\
(3.1 \%)\end{array}$ \\
\hline VCM & 2.6343 & 2.3669 & 2.3784 & 2.1461 \\
\hline
\end{tabular}

The grounding grid features used as program inputs are:

$$
\begin{aligned}
& d=0.01 \mathrm{~m} \quad \text { (diameter of the conductor) } \\
& D=0.5 \mathrm{~m} \quad \text { (depth of burial) } \\
& \rho=100 \Omega \mathrm{m} \text { (soil resistivity) }
\end{aligned}
$$

TABLE I

GROUND RESISTANCE

\section{B. Case Study 2}

This case study compares VCM with traditional method [6] for two grids in a soil stratified in two layers, rectangular grid and L-shape grid. To calculate the classic method was used the methodology of [13] to find the apparent resistivity. The features of the soil and of two ground grids used as program inputs are:

$\rho_{l}=200 \Omega \mathrm{m}$ (upper layer resistivity)

$\rho_{2}=400 \Omega \mathrm{m}$ (bottom layer resistivity)

$H=8 \mathrm{~m}$ (depth of the upper layer)

$D=0.5 \mathrm{~m}$ (depth of burial of ground grid)

$d=5 \mathrm{~mm}$ (wire diameter)

$\Delta L=5 \mathrm{~m}$ (distance between parallel conductors)

$i_{g}=1000 \mathrm{~A}$ (total current injected into the grid)

Fig. 2 show a rectangular grid with dimensions $35 \mathrm{~m} \times 20 \mathrm{~m}$ containing 28 meshes. The apparent resistivity seen by grid is $253.33 \Omega \mathrm{m}$. For the classic method the ground resistance was $4.87 \Omega$, the mesh voltage $\left(V_{m}\right)$ was $1019.95 \mathrm{~V}$ and the step voltage $\left(V_{s}\right)$ was $687.77 \mathrm{~V}$. With VCM the ground resistance was $4.66 \Omega$, the mesh voltage was $927.92 \mathrm{~V}$ in the corners, the maximum step voltage within the grid was $250.32 \mathrm{~V}$ and the step voltage in the corners was $509.82 \mathrm{~V}$.

Assuming a T-shaped grid as show in Fig. 3 with 18 meshes and dimensions $30 \mathrm{~m} \times 25 \mathrm{~m}$, the apparent resistivity seen by grid is $246.67 \Omega \mathrm{m}$. According IEEE Std. 80-2013 [6], the ground resistance was $6.00 \Omega$, the mesh voltage was $1278.20 \mathrm{~V}$ and the step voltage was $830.82 \mathrm{~V}$. Calculating by VCM the 
ground resistance was $5.40 \Omega$, the mesh voltage was $1168.56 \mathrm{~V}$ and the step voltage was $330.63 \mathrm{~V}$ within the grid and $639.80 \mathrm{~V}$ in the top corners.

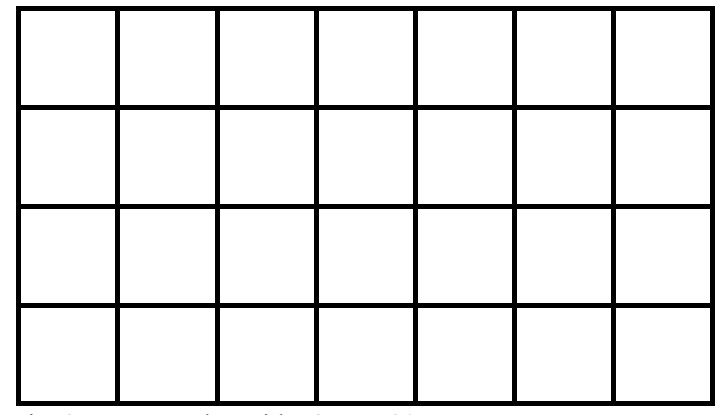

Fig. 2. Rectangular grid $-35 \mathrm{~m} \times 20 \mathrm{~m}$.

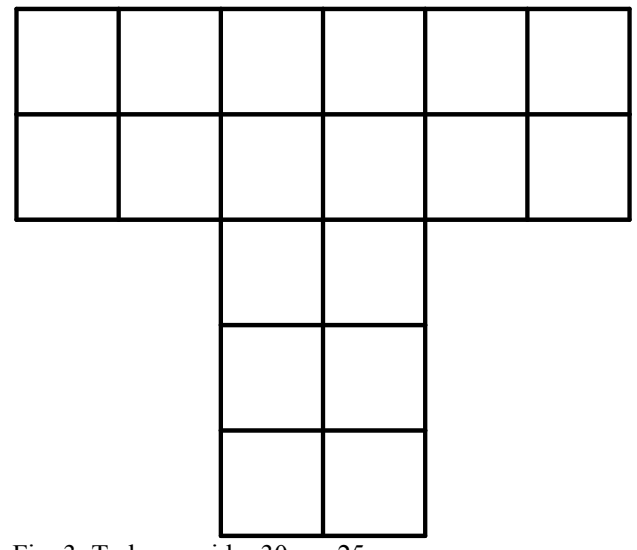

Fig. 3 T-shape grid $-30 \mathrm{~m} \times 25 \mathrm{~m}$.

Table II show the results found to the grids above with the difference of VCM to ANSI-IEEE Std. 80/2013.

TABLE II

PARAMETERS WITH IEEE STD. 80 AND VCM

\begin{tabular}{|c|c|c|c|c|}
\hline \multirow{2}{*}{ Grid } & \multirow{2}{*}{ Data } & \multicolumn{2}{|c|}{ Method } & \multirow{2}{*}{ Difference } \\
\hline & & Std. 80 & $V C M$ & \\
\hline \multirow{3}{*}{$\begin{array}{l}\text { Rectangular } \\
35 \mathrm{~m} \times 20 \mathrm{~m}\end{array}$} & $R_{g}(\Omega)$ & 4.87 & 4.66 & $4.31 \%$ \\
\hline & $V_{m}(\mathrm{~V})$ & 1019.95 & 927.92 & $9.02 \%$ \\
\hline & $V_{s}(\mathrm{~V})$ & 687.77 & 509.82 & $25.87 \%$ \\
\hline \multirow{3}{*}{$\begin{array}{l}\text { T-Shape } \\
30 \mathrm{~m} \times 25 \mathrm{~m}\end{array}$} & $R_{g}(\Omega)$ & 6.00 & 5.40 & $10.00 \%$ \\
\hline & $V_{m}(\mathrm{~V})$ & 1278.20 & 1168.56 & $8.58 \%$ \\
\hline & $V_{s}(\mathrm{~V})$ & 830.82 & 639.80 & $22.99 \%$ \\
\hline
\end{tabular}

\section{Case Study 3}

Figure 7 show a grounding grid of $120 \mathrm{~m} \times 80 \mathrm{~m}$, with variable spacing between the conductor. The profiles of the potential at the soil surface in the lines indicated by A,B,C and $\mathrm{D}$ obtained by the method proposed in this work are compared with the results of Huang [1]. The following input data used:

$\rho_{a}=200 \Omega \mathrm{m}$ (apparent ground resistivity)

$D=0.6 \mathrm{~m}$ (depth of burial of ground grid) $d=8.75 \mathrm{~mm}$ (wire diameter)

$i_{g}=10000 \mathrm{~A}$ (total current injected into the grid)

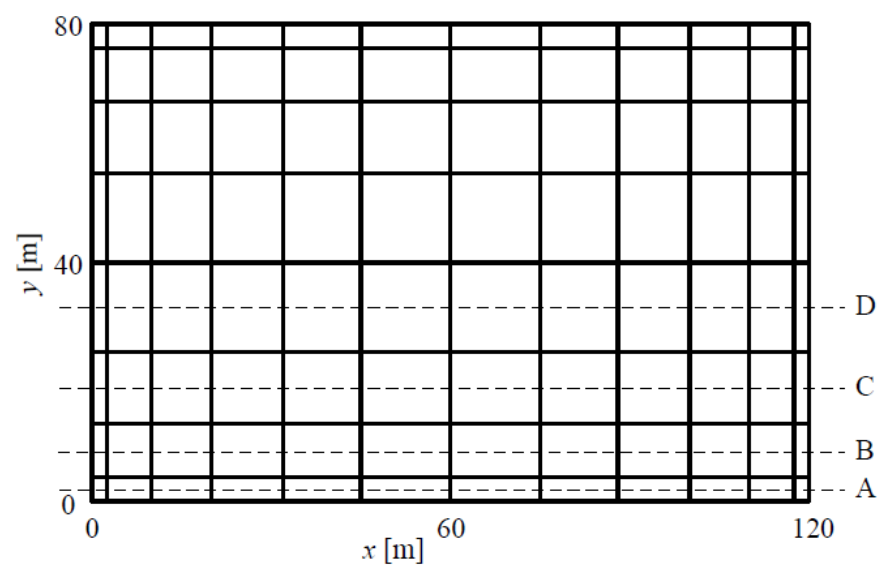

Fig. 7 Grounding grid with different spacing.

Figure 8 shows the potential on the soil surface profile obtained.

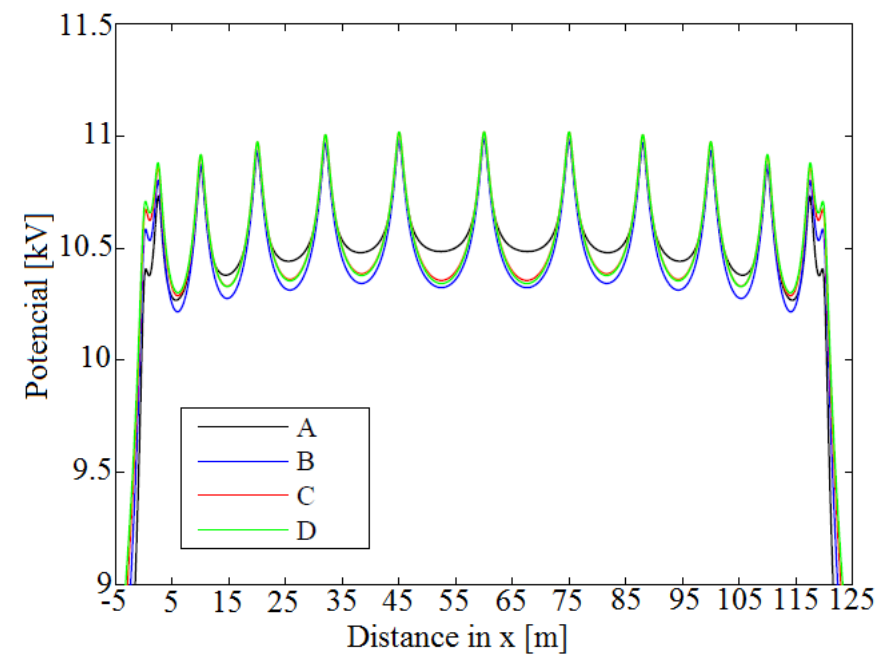

Fig. 8 Profiles on the soil surface, results obtained by the proposed method.

The potential on the soil surface with geographic location of coordinates $\mathrm{x}=1.25 \mathrm{~m}$ and $\mathrm{y}=2.0 \mathrm{~m}$, obtained in the work of Huang [1] is $10.37 \mathrm{kV}$ while by the proposed method is $10.40 \mathrm{kV}$. The result obtained for the soil surface potential with geographic location of coordinates $\mathrm{x}=52.5 \mathrm{~m}$ and $\mathrm{y}=32.5 \mathrm{~m}$ in the work of Huang [1] is $10.23 \mathrm{kV}$ and by the proposed method is $10.34 \mathrm{kV}$.

Figure 9 shows the distribution of the equipotential through isolines. Potential peaks observed at the intersections of the electrodes, except at the border of the grid where potential reduction occurs. The maximum potential at the soil surface occurs in coordinate $\mathrm{x}=60 \mathrm{~m}$ and $\mathrm{y}=40 \mathrm{~m}$, with a value of $11.33 \mathrm{kV}$. 


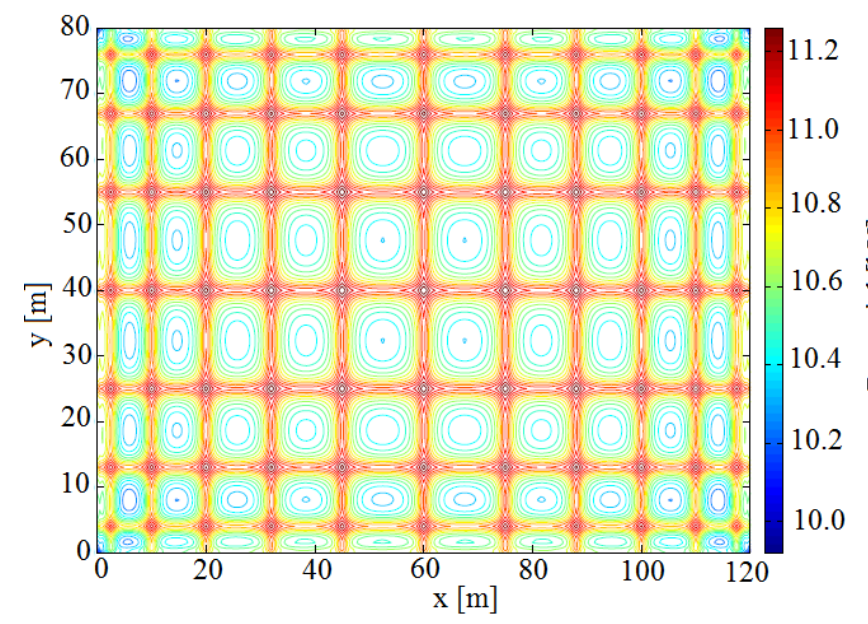

Fig. 9 Equipotential distributed on the soil surface.

The maximum surface potential obtained at the central point of the grid due to the symmetrical distribution of the electrodes around the point.

\section{Case Study 4}

It presented a grid composed of conductors at different angles and different lengths as show in the Fig. 10. The grid has 16 meters in the $\mathrm{x}$-axis and 17 meters in the $\mathrm{y}$-axis [14]. The following input data were used:

$\rho_{l}=200 \Omega \mathrm{m}$ (upper layer resistivity)

$\rho_{2}=400 \Omega \mathrm{m}$ (bottom layer resistivity)

$H=8 \mathrm{~m}$ (depth of the upper layer)

$D=0.5 \mathrm{~m}$ (depth of burial of ground grid)

$d=5 \mathrm{~mm}$ (wire diameter)

$i_{g}=1200 \mathrm{~A}$ (total current injected into the grid)

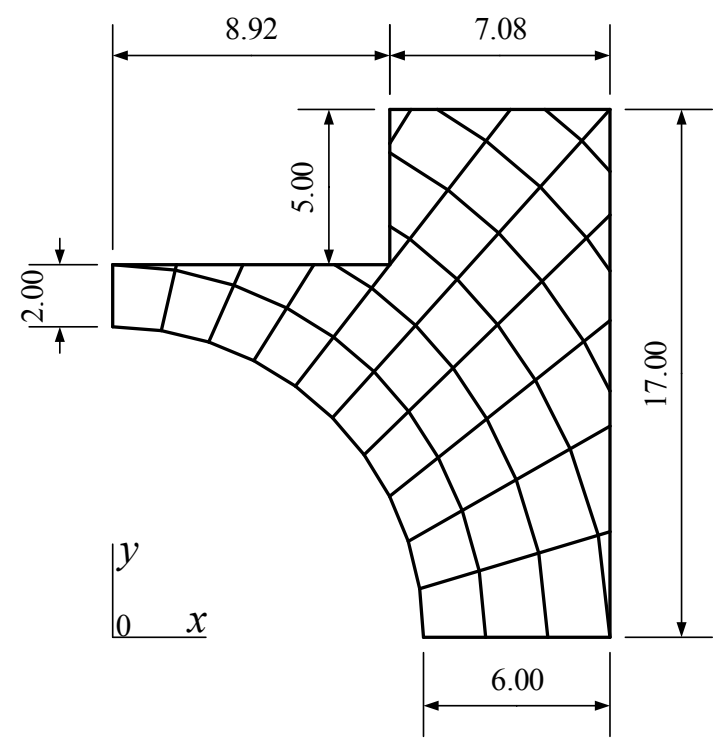

Fig. 10 Unconventional grid.

Fig. 11 shows the voltage profile in three dimensions and contour of the soil surface potential inside the perimeter of the ground grid.

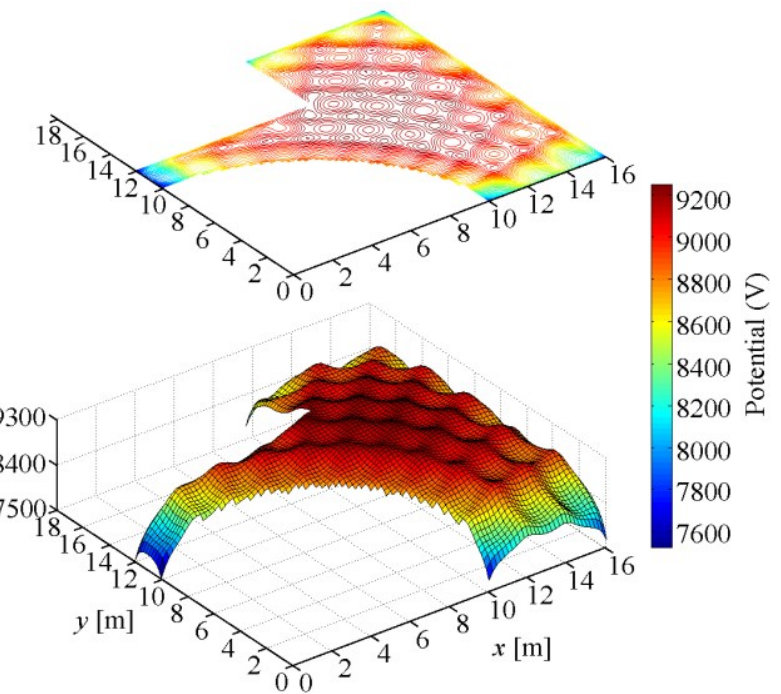

Fig. 11 Surface Potential.

All voltages calculated for points on the surface located within the perimeter of the mesh. The value obtained for the ground resistance was $8.0 \Omega$, for mesh voltage was $2075.98 \mathrm{~V}$ at the coordinates $\mathrm{x}=0 \mathrm{~m}$ and $\mathrm{y}=10 \mathrm{~m}$; and the maximum step voltage was $925.04 \mathrm{~V}$ between the point of coordinates $\mathrm{x}_{1}=16 \mathrm{~m}$ and $\mathrm{y}_{1}=17 \mathrm{~m}$, and the point of coordinates $\mathrm{x}_{2}=15.36 \mathrm{~m}$ and $\mathrm{y}_{2}=16.23 \mathrm{~m}$. The GPR was $9595.60 \mathrm{~V}$ and the maximum surface voltage $\left(V_{\text {sur }}\right)$ is $9245.45 \mathrm{~V}$ at the coordinates

$$
\mathrm{x}=9.8 \mathrm{~m} \text { e } \mathrm{y}=10.0 \mathrm{~m} \text {. }
$$

\section{Study Case 5}

The study case presented to verify the influence of the depth of the grounding grid, the ground grid used shown in Figure 10 , and the depth varied from $0.5 \mathrm{~m}$ to $3.5 \mathrm{~m}$. The potential profiles on the surface were obtained from the cut at $\mathrm{y}=11 \mathrm{~m}$ in the grounding grid shown in Figure 10. Table III show the values obtained for the resistance of the grounding grid, GPR, the maximum potential at the ground surface, the touch voltage and the maximum step voltage for different depths of the ground grid. The following input data used:

$\rho_{l}=200 \Omega \mathrm{m}$ (upper layer resistivity)

$\rho_{2}=400 \Omega \mathrm{m}$ (bottom layer resistivity)

$H=2 \mathrm{~m}$ (depth of the upper layer)

$D=0.5 \mathrm{~m}-3.5 \mathrm{~m}$ (depth of burial of ground grid)

$d=5 \mathrm{~mm}$ (wire diameter)

$i_{g}=1200 \mathrm{~A}$ (total current injected into the grid)

The Table IV show the coordinate maximum of the surface potential and step voltage.

Fig.12 and Fig.13 shows the elevation of the ground resistance values and the GPR of the ground grid, which are directly proportional. 
TABLE III

GROUNDING GRID PARAMETERS AT DIFFERENT DEPTHS

\begin{tabular}{llllll}
\hline \hline $\mathbf{D}(\mathbf{m})$ & $\mathbf{R}_{\mathbf{g}}(\boldsymbol{\Omega})$ & $\mathbf{G P R}(\mathbf{V})$ & $\mathbf{V}_{\mathbf{s}}(\mathbf{V})$ & $\mathbf{V}_{\text {touch }}(\mathbf{V})$ & $\mathbf{V}_{\text {step }}(\mathbf{V})$ \\
\hline 0.5 & 9.93 & 11916.08 & 11626.38 & 2377.19 & 1103.1 \\
1.0 & 9.64 & 11565.18 & 11223.86 & 2771.30 & 984.57 \\
1.5 & 9.48 & 11371.17 & 10984.02 & 3040.44 & 847.52 \\
1.6 & 9.46 & 11350.29 & 10948.32 & 3094.98 & 826.73 \\
1.7 & 9.45 & 11337.78 & 10917.37 & 3154.29 & 808.28 \\
1.8 & 9.45 & 11337.74 & 10892.96 & 3223.90 & 792.26 \\
1.9 & 9.47 & 11363.41 & 10881.04 & 3320.62 & 779.05 \\
2.0 & 9.68 & 11620.32 & 10965.79 & 3687.02 & 773.77 \\
2.1 & 16.89 & 20270.30 & 11231.81 & 12577.11 & 762.37 \\
2.2 & 16.85 & 20219.40 & 11140.67 & 12611.32 & 739.89 \\
2.3 & 16.78 & 20138.91 & 11047.19 & 12610.62 & 718.45 \\
2.4 & 16.71 & 20050.57 & 10953.58 & 12598.41 & 698.02 \\
2.5 & 16.63 & 19960.81 & 10860.20 & 12581.82 & 678.55 \\
3.0 & 16.29 & 19549.73 & 10396.24 & 12501.50 & 593.77 \\
3.5 & 16.02 & 19224.64 & 9937.84 & 12459.86 & 525.35 \\
\hline \hline
\end{tabular}

TABLE IV

COORDINATE MAXIMUM OF THE SURFACE POTENTIAL AND STEP VOLTAGE.

\begin{tabular}{|c|c|}
\hline Parameter & Coordinates \\
\hline $\mathrm{V}_{\text {step }}$ & $\begin{array}{l}\mathrm{x}=16.0 \mathrm{~m} \text { and } \mathrm{y}=17.0 \mathrm{~m} \\
\mathrm{x}=12.4 \mathrm{~m} \text { and } \mathrm{y}=16.3 \mathrm{~m}\end{array}$ \\
\hline $\mathrm{V}_{\mathrm{s}}$ & $\mathrm{x}=0 \mathrm{~m}$ and $\mathrm{y}=20 \mathrm{~m}$ \\
\hline
\end{tabular}

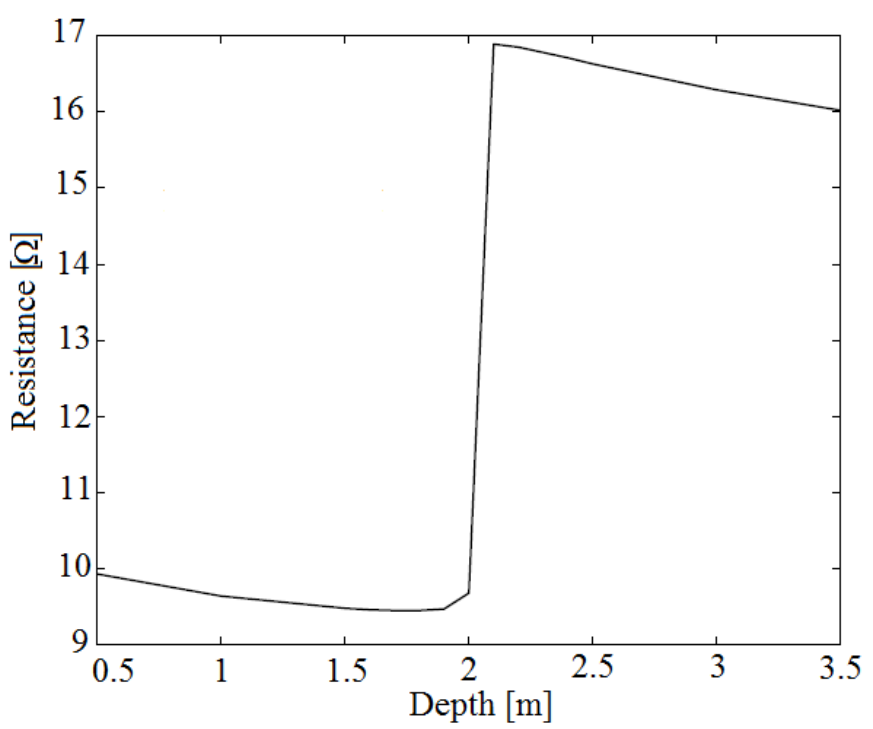

Fig. 12 Resistance $\left(R_{g}\right)$ versus depth $(D)$.

The boundary between the first and second soil layers occurs exactly in $\mathrm{D}=2 \mathrm{~m}$. The potential on the soil surface increases in the depths just below to this border (Figure 14).

Figure 15 shows the increase of the touch voltage near the boundary between the soil layers, since the grounding grid when positioned in the second soil layer, which has a higher resistivity $(400 \Omega . m)$ in relation to the first layer that has lower resistivity $(200 \Omega . \mathrm{m})$, produces higher touch potential.

Figure 16 shows that the pitch voltage decreases smoothly with increasing depth, having a level in the depths near the boundary between the layers.

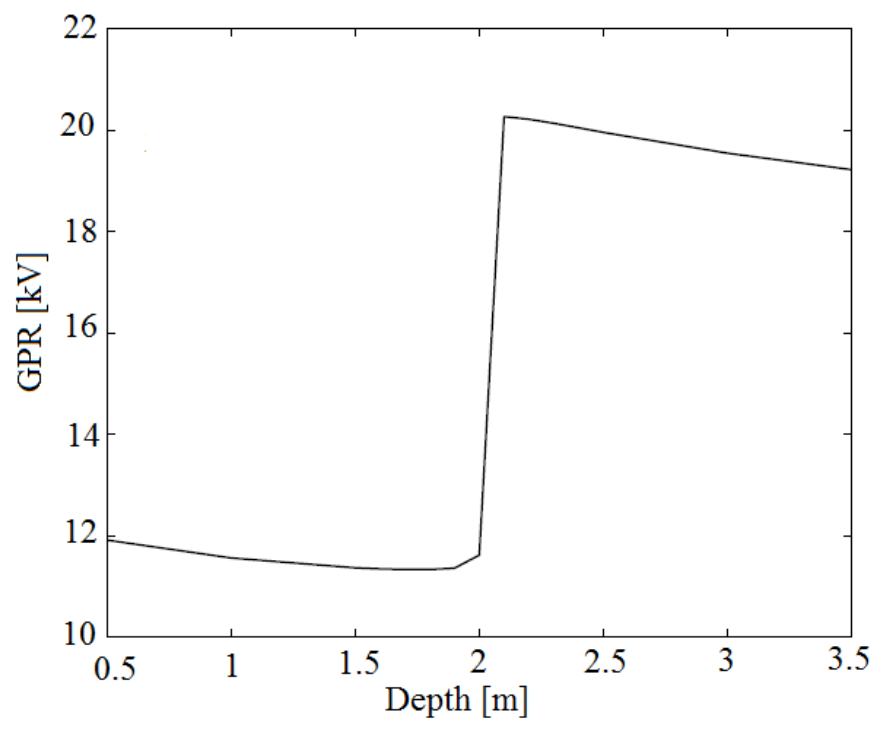

Fig. 13 GPR versus depth $(D)$.

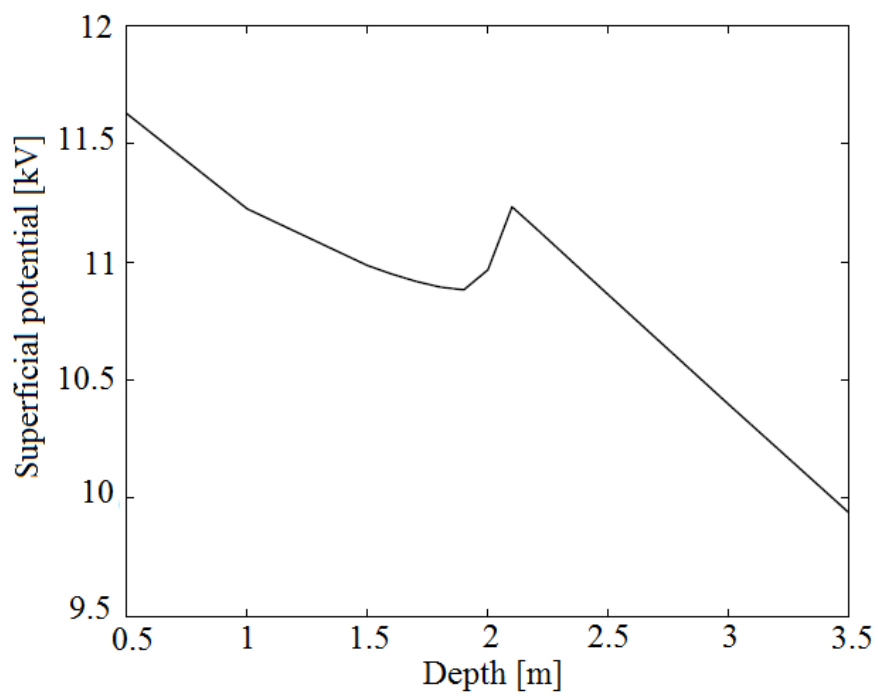

Fig. 14 Superficial potential $\left(V_{s}\right)$ versus depth $(D)$.

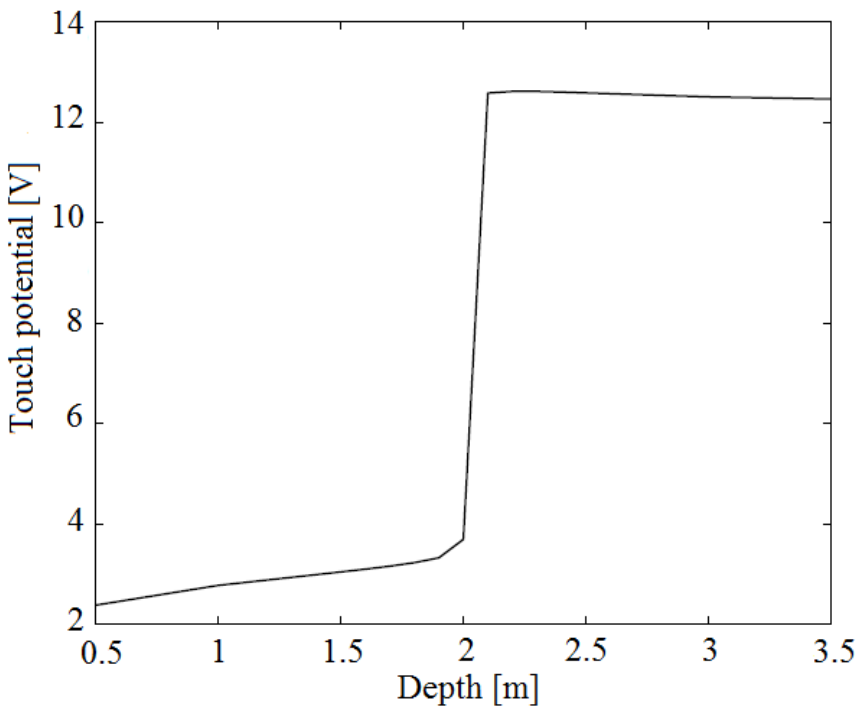

Fig. 15 Touch potential $\left(V_{t}\right)$ versus depth $(D)$. 


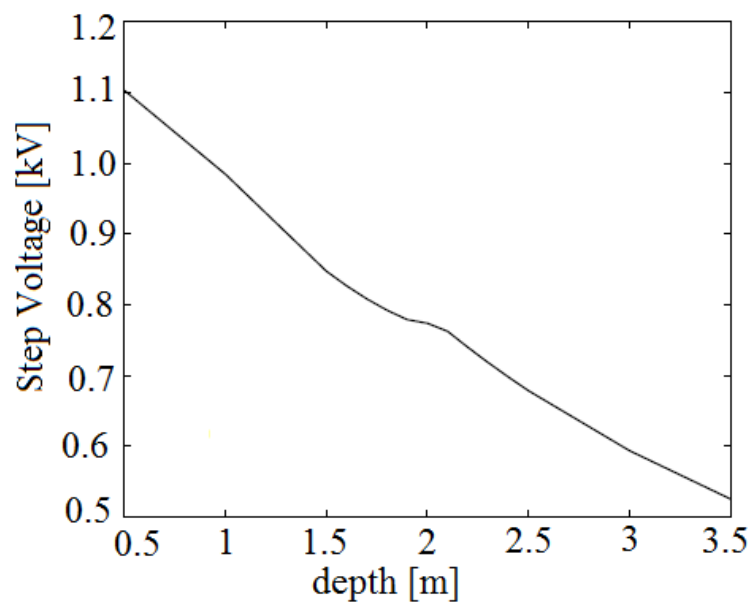

Fig. 16 Surface Potential.

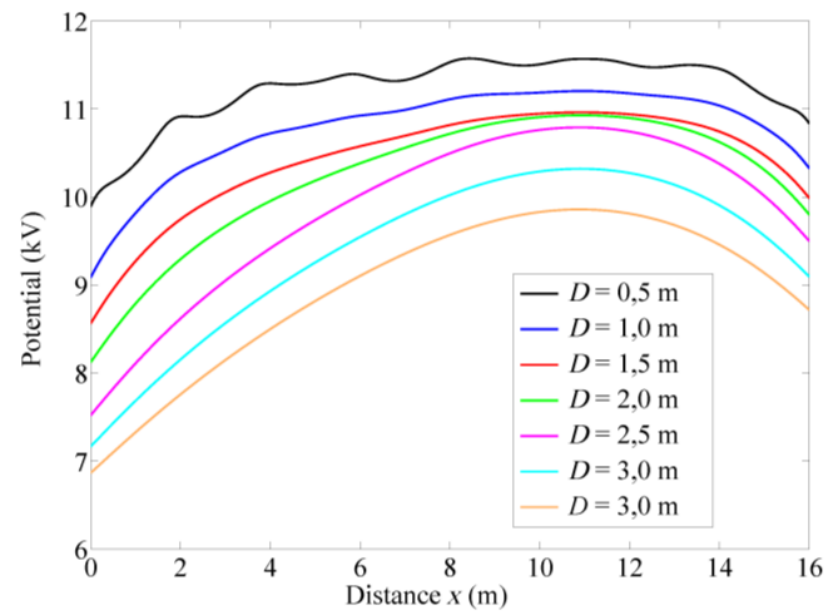

Fig. 17 Surface Potential.

Figure 17 illustrates the potential profiles at the soil surface at $y=11 \mathrm{~m}$ for the different depths of the grounding grid, where it is observed, reduction of potential with the increase of the depth of the grounding grid, reduction in the number of peaks along the distance.

\section{CONCLUSION}

The method implemented in this paper allows the computation of the ground resistance, grid voltage and step voltage of grids composed by horizontal wire electrodes in shapes that are more complex. Wire segments can have any position or displacement among them.

The difference between the results obtained with this method and those of the ANSI-IEEE Std. 80/2013 for the grounding resistance was up to $25.5 \%$. For grid voltage was up to $16.6 \%$ and $41.9 \%$ for step voltage. The individual calculation of the leakage current for each segment leads to a greater precision of the method.

This method also proves to be useful for allowing a precise analysis of the voltage on the soil surface, it is possible to calculate the voltage at any desired point. Also, the detailed study of any grounding grid at any depth in the soil is possible.

\section{ACKNOWLEDGEMENT}

The authors thank the National Counsel of Technological and Scientific Development (CNPq), Coordination for the Improvement of Higher Level Personnel (CAPES) and the Research Support Foundation for the State of Goias (FAPEG) for financial assistance to this research.

\section{REFERENCES}

[1] L. Huang, X. Chen, and H. Yan, "Study of unequally spaced grounding grids," Power Delivery, IEEE Transactions on, vol. 10, pp. 716-722, 1995.

[2] IEEE, "Guide for Safety in AC Substation Grounding," in IEEE Std 80 (Revision of IEEE Std 80-2000/ Incorporates IEEE Std 80-2013/Cor 12015), ed, 2015.

[3] B. Thapar, V. Gerez, A. Balakrishnan, and D. A. Blank, "Simplified equations for mesh and step voltages in an AC substation," Power Delivery, IEEE Transactions on, vol. 6, pp. 601-607, 1991.

[4] A. Covitti, G. Delvecchio, A. Fusco, F. Lerario, and F. Neri, "Two Cascade Genetic Algorithms to Optimize Unequally Spaced Grounding Grids with Rods," in Computer as a Tool, 2005. EUROCON 2005. The International Conference on, 2005, pp. 1533-1536.

[5] A. J. Heppe, "Computation of Potential at Surface Above an Energized Grid or Other Electrode, Allowing for Non-Uniform Current Distribution," Power Apparatus and Systems, IEEE Transactions on, vol. PAS-98, pp. 1978-1989, 1979.

[6] "IEEE Guide for Safety in AC Substation Grounding," IEEE Std 802013 (Revision of IEEE Std 80-2000/ Incorporates IEEE Std 802013/Cor 1-2015), pp. 1-226, 2015.

[7] H. B. Dwight, "Calculation of Resistances to Ground," American Institute of Electrical Engineers, Transactions of the, vol. 55, pp. 1319$1328,1936$.

[8] J. G. Sverak, "Sizing of Ground Conductors Against Fusing," Power Apparatus and Systems, IEEE Transactions on, vol. PAS-100, pp. 5159, 1981.

[9] S. J. Schwarz, "Analytical Expressions for the Resistance of Grounding Systems [includes discussion]," Power Apparatus and Systems, Part III. Transactions of the American Institute of Electrical Engineers, vol. 73, 1954.

[10] J. Nahman and S. Skuletich, "Irregularity Correction Factors for Mesh and Step Voltages of Grounding Grids," Power Apparatus and Systems, IEEE Transactions on, vol. PAS-99, pp. 174-180, 1980

[11] Y. L. Chow and M. M. A. Salama, "A simplified method for calculating the substation grounding grid resistance," Power Delivery, IEEE Transactions on, vol. 9, pp. 736-742, 1994.

[12] S. S. M. Ghoneim, "Optimization of grounding grids design with evolutionary strategies," Thesis (PhD), Faculty of Enginnering Sciences, Univeristät Duisburg-Essen, Duisburg, Germany, 2007.

[13] J. Endrenyi, "Evaluation or Resistivity Tests for Design of Station Grounds in Nonunirorm Soil," Power Apparatus and Systems, IEEE Transactions on, vol. 82, pp. 966-970, 1963.

[14] Pires, Thyago G. ; Nerys, Jose W. L. ; Silva, Carlos L. B. ; Oliveira, Diogo N. ; Filho, Antonio M. Silva ; Calixto, Wesley P. ; Alves, Aylton J., Computation of resistance and potential of grounding grids in any geometry. In: 2016 IEEE 16th International Conference on Environment and Electrical Engineering (EEEIC), 2016, Florence. 2016 IEEE 16th International Conference on Environment and Electrical Engineering (EEEIC), 2016.

[15] Pires, Thyago G. ; Silva, Carlos L. B. ; Oliveira, Diogo N. ;Nerys, Jose W. L. ; Alves, Aylton J.; Calixto, Wesley P. Computation of grounding grids parameter on unconventional geometry. In: 2015 CHILEAN Conference on Electrical, Electronics Engineering, Information and Communication Technologies (CHILECON), 2015, Santiago. 2015. 